\title{
Enhancing the hospitality customer experience of families with children on the autism spectrum disorder
}

Daniela Freund, Monica Cerdán, Gilda Hernández-Maskivker -Research Group in Tourism, Hospitality and Mobilities, School of Tourism and Hospitality Management Sant Ignasi, Universitat Ramon Llull, Barcelona, Spain

Mireia Guix

-Research Group in Tourism, Hospitality and Mobilities, School of Tourism and Hospitality Management Sant Ignasi, Universitat Ramon Llull, Barcelona, Spain

-School of Management, Universidad del Rosario, Bogotá, Colombia

Ana Iñesta

-Center for Educational Innovation, ESADE Business \& Law School, Universitat Ramon Llull, Barcelona, Spain

Montserrat Castelló

-Facultat de Psicologia, Ciències de l'educació i l'Esport, Universitat Ramon Llull, Barcelona, Spain

The research has been carried out through funds from "la Caixa" Foundation, Spain. Grant number: 2017 - URL - Internac - 024.

\begin{abstract}
The purpose of this study is to examine intention to travel to accessible accommodations by families of children diagnosed with autism spectrum disorder (ASD), the influence of travel constraints (intrinsic, interactive, and environmental), the severity of disorder, and the families' strategies for coping with such constraints. A structured survey targeted at Spanish families $(N=117)$ indicated that the intrinsic dimension and the severity of disorder positively influence their intention to travel. The study contributes to extend knowledge about travel constraints related to accessible tourism and provides insights to accommodation providers on how to better enhance the customer experience of families travelling with a child diagnosed with ASD.
\end{abstract}

\section{KEYWORDS}

Accessible tourism, autism spectrum disorder, family tourism, disability studies, customer experience, constraints, hospitality

\section{INTRODUCTION}

Accessible tourism encloses people with mobility, vision, hearing, cognitive, and developmental disabilities (Darcy, 2010). It is a significant emerging market that yet 
remains an issue for the tourism industry. By 2020, Europe is expected to have 120 million people with disabilities, with an internal demand for European Union's accessible tourism up to 862 million trips per year and an inbound market of 21 million trips per year (European Commission, 2013). Worldwide públic and private organisations are fostering inclusive tourism from the demand and supply side (European Commission, 2016; Hausemer, Ambrose, Ito, \& Auzinger, 2012; World Tourism Organization, 2015). Yet accessibility remains a significant challenge for the travel and tourism sector.

This study responds to the call for further research on understanding the distinct needs faced by different segments of the accessibility market (Buhalis \& Michopoulou, 2011; McKercher \& Darcy, 2018). Despite this growing interest both from practitioners and researchers in accessible tourism, research has particularly focused on physical disabilities or a mixture of disabilities with scarce research investigating specifically developmental disorders. The purpose of this study is to examine intention to travel to accessible accommodations by famílies of children diagnosed with autism spectrum disorder (ASD), in particular, the influence of travel constraints (intrinsic, interactive, and environmental), the degree of disorder, and the families' strategies for coping with such constraints.

According to Perry and Kozub (2011), there is considerable research on travel related issues for people with physical disabilities (Burnett \& Baker, 2001, Darcy 2002, Yau, McKercher, \& Packer, 2004), but little is known about the travel experiences of famílies where one member has a developmental disorder (Sedgley, Pritchard, Morgan, \& Hanna, 2017; Woodside \& Etzel 1980). The World Health Organization (WHO, 2014) urged its Member States to identify and address disparities in access to services for persons diagnosed with ASD. About $1 \%$ of the world population is diagnosed with ASD (CDC, 2014) being the fastest growing developmental disorder (CDC, 2018). Its prevalence is one child out of 59 and has increased by $6-15 \%$ each year from 2002 to 2010, based on biennial numbers from the CDC, which indicates an increased trend over the past 30 years (America's Centers for Disease Control and Prevention, 2018). At the present time, persons on ASD represent an underacknowledged segment of travellers with unique travel needs, and this type of families is one of the segments underresearched by academia (Schänzel, Yeoman, \& Backer, E. (Eds,)., 2012; Hamed, 2013; Stuhl \& Porter, 2015).

This is a nascent area of tourism research, and this target group represents a segment of the travelling population that is likely to grow significantly in the years to come. Improved understanding of the needs of families with children diagnosed with ASD when staying at hotels or similar accommodation and their intention to travel to accessible accommodation could lead to improvement in access to services, safety, and customer satisfaction. The purpose of this study is to provide a starting point to better understand this neglected traveller population and their constraints when travelling to accommodation facilities. On one hand, it will hopefully encourage more and more specialised publications. On the other hand, there is a lack of international standards regarding developmental disorders to guide tourism and hospitality professionals, so this study will contribute in this respect.

This study is structured in four sections. First, it explains the context of accessible tourism, and earlier research on the ASD and tourism behaviour. Second, it describes the hypothesis and methods used. Third, it presents the findings and discussion. Finally, the study presents its contribution to literature and management practices and suggests further research. 


\section{LITERATURE REVIEW}

People diagnosed with ASD are characterised "by some degree of impaired social behaviour, communication, and language, accompanied by a narrow range of interests and activities that are both unique to the individual and carried out repetitively" (WHO, 2014). The autism condition is a "life-long neurodevelopment condition interfering with the person's ability to communicate and relate to others" (Elsabbagh et al., 2012:160). Hamed (2013) defines autism as a complex developmental condition that results from a neurological disorder that affects the normal functioning of the brain. It impacts communicative, social, and behavioural development, often accompanied by difficulties in cognitive functioning, learning, attention, and sensory processing. The symptoms typically appear during the first 3 years of life. People affected by this disorder usually have poor eye contact and Language delay and exhibit stereotyped or repetitive behaviour. In some case, they ignore others, as they are unable to successfully communicate and interact with them, and often seem to be self - absorbed in their own private world (Autism Speaks, 2010; Early Intervention Consulting, 2011; Kopetz \& Endowed, 2012; National Institute on Deafness and Other Communication Disorders NIDCD, 2010). These characteristics were understood as a range of diagnoses under the umbrella term of "pervasive developmental disorders." Nowadays, the American Psychiatric Association (2013) categorises all such mental health issues, in the broader diagnosis of ASD (including Asperger's disorder). Rett disorder is the only one remaining independent.

Being a spectrum disorder, the symptoms and characteristics of autism can reveal themselves in a wide variety of combinations and ranges from mild to severe. At one end of the spectrum of autism, individuals tend to have many challenging behaviours. Mainly, they confront social, communication, and behavioural challenges (Hamed, 2013). At the other end, individuals have full cognitive abilities and can communicate well with spoken language. Thus, symptoms will present in each individual differently. Two individuals both with a diagnosis of ASD can act very differently from one another. It is said that "if you know one person with autism; you know one person with autism." So, although there is neither one definitive definition nor two individuals on the ASD are alike, it is agreed that the diagnosis does have an impact on the life of the individual diagnosed and their families. Although each individual presents heterogeneity of symptoms and capabilities within the spectrum, researchers distinguish three main groups, given their severity of symptoms and characteristics: high functioning (0-33\%), middle functioning (34-65\%), or low functioning (+65\%; Dawson, 1996; Hamed, 2013).

The academics and tourism providers' understanding of disabilities and its integration with the community influence the tourism sector. Existing disability models take different approaches that parallel an inclusion process (Darcy, Cameron, \& Pegg, 2010; Figueiredo, Eusébio, \& Kastenholz, 2012; Kim \& Lehto, 2013; Zajadacz, 2015): from social exclusion (medical approach), integration (social approach), and inclusion (bio-psychological and geographical). The medical model understands disability as a personal tragedy that needs to be alleviated, and therefore, the individual is responsible for his/her adaptation to the environment (Zajadacz, 2015). The medical model leads to the creation of separated offer, for example, health tourism. Instead, at the social model, disability is seen as a potential pool of demand that service providers can explore developing targeted products that adapt the environment to the needs of the market segment (Zajadacz, 2015). The social model results in products creating the conditions for making the travel as accessible as possible. Alternatively, the biopsychological and geographical models appear as a synthesis of the previous, where 
disability is seen as individual characteristics that both require medical assistance and include people with disabilities in society as a social responsibility. These last models focus on social inclusion through a universal design approach that facilitates the resources to preserve a quality standard of living.

This study positions the research within inclusive models, closely related to the principle Design for all, aligned with the tourism for all concept (Michopoulou, Darcy, Ambrose, \& Buhalis, 2015; Portales, 2015). The universal design encompasses the needs of all society members, seeing people with disabilities as one of many different profiles in society. Tourism for all fosters travel and leisure without barriers for every disability community. The positioning within an inclusive model permeates the specific language use and nomenclatures of this paper because "language provides a unique capability to resist, strengthen and reframe identities of individuals and groups, yet can also reinforce, weaken and perpetuate dominant worldviews of disability" (Gillovic et al., 2018:1). In this respect, we have opted to use "children diagnosed with ASD," "children on ASD," "condition or disorder" when referring to the ASD, and "person with disabilities" aligned with a social model approach.

As mentioned in Section 1, accessible tourism research has primarily focused on physical disabilities or a mixture of disabilities. From the demand side, research has focused on attitudinal barriers (Bi, Card, \& Cole, 2007) and experiences in travel (Daniels, Rodgers, \& Wiggins, 2005) and hospitality services (Lugosi, Robinson, Golubovskaya, Foley, \& Harwell, 2016). From the supply side, research has studied the provision of (a) accessible tourist attraction and sites (Israeli, 2002), (b) accessible accommodation information (Buhalis \& Michopoulou, 2011; Darcy, 2010), and (c) hotel experiences (Darcy \& Pegg, 2011; O'Neill \& Ali Knight, 2000). Yet research on families with children with developmental difficulties has received less attention in tourism research, which has focused on analysing the leisure constraints (Emira \& Thompson, 2011), travel (Perry \& Kozub, 2011) and vacation experiences (Amet, 2013), and the effectiveness of travel agents (Hamed, 2013; McKercher, Packer, Yau, \& Lam, 2003). Thus, research on tourism and developmental disorders is anecdotal (Hamed, 2013), as is research on accessibility in hotels and family tourism (Schänzel et al., 2012).

Families play a major role when travelling together with a child with developmental disorders, though the hospitality consumption experiences of parents and carers with children remains underexamined (Lugosi et al., 2016; Sedgley et al., 2017). Although research usually focuses on the person with disability, families' opinions also should be taken into account (Emira \& Thompson, 2011). For instance, travelling can be overwhelming for a child diagnosed with ASD and its family, as it "involves changes in routine, anxiety and dealing with sensory issues" (Hamed, 2013:1). The lack of recreational time added to the pressure of constant dealing with a person with dependence is considered an extra source of stress (Kim \& Lehto, 2013), which travel may contribute to reduce. Research evidences the positive impact leisure has on both the child's life (Kim \& Lehto, 2013; Lee, Agarwal, \& Kim, 2012) and family members (Lugosi et al., 2016). Tourism - and leisure-related experiences provide benefits such as improvement in happiness levels, health conditions, self-esteem, freedom from stress, levels of satisfaction, and social inclusion (Darcy \& Dickson, 2009; Hamed, 2013; Stuhl \& Porter, 2015).

Despite benefits derived from travel, earlier research, not including developmental disorders, identified that the disability level impacts on the travel experience (Bi et al., 2007; Burnett \& Baker, 2001; McKercher \& Darcy, 2018). Dwyer and Darcy (2008) demonstrated, using the Australian Bureau of Statistics Disability (2004), that while 
travelling, those having a disability can have different levels of independence and support needs ranging from none, mild, moderate, severe, to profound (24-hr assistance).

Travel intention is "an outcome of a mental process that leads to an action and transforms motivation into behaviour" (Jang, Bai, Hu, \& Wu, 2009, p. 57). As noted by several authors, it is important to qualify that it does not always translate into actual travel behaviour (Decrop, 2006; Kah, Lee, \& Lee, 2016; March \& Woodside, 2005). Intention to travel has been used to predict travel behaviour (Jang et al., 2009; Kah et al., 2016) because it emphasises commitment to travel. Therefore, it is important to measure intention to travel to accurately examine what travellers are likely to do (Jang et al., 2009). Intention to travel is "in part, formed by overcoming various constraints which may be present at various stages of the decision-making process" (Lee et al., 2012, p. 570). In their view, people with disabilities give up travel opportunities despite sufficient mobility and accessibility, due to varied constraints.

Several researchers have identified travel-related and multidimensional constraints confronted by people with disabilities (e.g., Bi et al., 2007; Daniels et al., 2005; Israeli, 2002; Lee et al., 2012; McKercher et al., 2003; Poria, Reichel, \& Brandt, 2011; Shaw \& Coles, 2004; Turco, Stumbo, \& Garncarz, 1998; Yau et al., 2004). The main constraints are typically classified into intrinsic (intrapersonal), interactional (interpersonal), or environmental (structural; Crawford \& Godbey, 1987; Crawford, Jackson, \& Godbey, 1991). Intrinsic constraints relate to an individual's psychological condition and include personality factors, attitudes, religious beliefs, and moods (Crawford et al., 1991; Crawford \& Godbey, 1987). Interactional constraints arise from social interaction with others, including skills, challenges, and communication barriers (Allan, 2015; Smith, 1987). Environmental constraints, which have been extensively identified, come mainly from the lack of adequate destination facilities (McKercher et al., 2003; Poria et al., 2011). The lack of qualified staff and their attitude (Emira \& Thompson, 2011), availability of accessibility-related information (Darcy, 2010; Lee et al., 2012; Shaw \& Coles, 2004; Yau et al., 2004), and own environment perception (Amet, 2013) may aggravate the barriers. The above constraints are prominent in accessible tourism accommodation, which is a prerequisite for the destination choice (Market and Communication Research, 2002). Also coping strategies of caregivers are starting to be researched; first results include looking in advance for accommodation that could provide for the child's needs (Sedgley et al., 2017). Thus, intrinsic, interactional, and environmental constraints are expected to influence the travel intention to accessible accommodations.

Still, there is a need for understanding the uniqueness of the challenges faced by each disability community (McKercher \& Darcy, 2018) as both the nature of disability and the degree of impairment, suport needs, and level of independence significantly influence the perceived constraints (Emira \& Thompson, 2011), the intention to travel (Lee et al., 2012), and the final accommodation choices (Burnett \& Baker, 2001; Darcy, 2010). Most research on constraints on accommodation focuses on physical disability (Darcy, 2010; Poria et al., 2011), whereas accommodation managers and owners often do not recognise disability as a market (Darcy, 2010; O'Neill \& Ali Knight, 2000) and only inform on whether the establishments have a "disabled room" (Tantawy, Kim, \& Pyo, 2005). To sum up, this study specifically focuses on the intention to travel of families with children diagnosed with ASD to accessible accommodation, this type of families being one of the segments underresearched by academia (Hamed, 2013; Stuhl \& Porter, 2015). This research is part of a larger project that explores the families with a child on ASD as a market segment, examines their intention to travel, understands their emotional experience, provides insights for further academic 
research and recommendations to engage more autism-friendly accommodation providers. The research project was approved by the ethics committee of the Universitat Ramon Llull (Reference Number 2504/16). Four hypotheses were researched that act as the framework of the study:

Hypothesis 1. The travel constraints of intrinsic nature influence the intention to travel to accessible accommodation of families with children on ASD.

Hypothesis 2. The travel constraints of interactive nature influence the intention to travel to accessible accommodation of families with children on ASD.

Hypothesis 3. The travel constraints of environmental nature influence the intention to travel to accessible accommodation of families with children on ASD.

Hypothesis 4. The higher the degree of disorder of the child on ASD, the higher the intention to travel to accessible accommodation of their families.

\section{METHODS}

An exploratory approach with a cross-sectional design was adopted, testing the above hypothesis. Because the study aimed to measure the intention to travel against the established dimension of the target population, a self-administered on-line survey was chosen. A convenience sampling technique was selected, being the target population 150 families with children on the autism spectrum living in Catalonia (Spain). Participants were parents with a child on ASD that were members of Autism Association Aprenem, the Institute of Diagnosis and Psychiatric and Psychological Support IDAPP, and the School of Special Education Paidea, which are leading institutions in Catalonia that cater to children on the ASD. As previous literature on these issues highlight, these types of collaborations between acadèmics and specific organizations enable both to benefit from acadèmic research skills and credibility and to ensure the priorities of famílies with children diagnosed with ASD are considered in the research (Sedgley et al., 2017).

The data collection was carried out in December 2016 (150), and 117 usable online surveys were collected, filled by parents. Online surveys allowed families to respond openly and take the time necessary to answer. Families had the support of the researchers throughout the data collection process to solve doubts and clarify questions. The survey consisted of two themes: accommodation-related constraints and socio-demographic profile, organised in seven variables informed by previous studies. Socio-demographic questions collected included gender, number of members in the family, marital status, education, and monthly household income of the respondent. Furthermore, demographic data related to the child were requested such as, age, gender, and severity of disorder. Travel-related characteristics of the sample were also collected: overnight travel experience, number of trips, and average length of stay. The survey used 5-point Likert scale, as previous literature that studied attitudes and constraints in the hospitality sector (Allan, 2015; Kim \& Lehto, 2013). Open-ended questions, based on the ecological approach and social model of disability of Poria et al. (2012), were included in the survey and analysed. Questions were (a) related to critical incidents or difficulties encountered by the families at the accommodation facility, (b) families' coping strategies, and (c) suggestions to accommodation providers. 
The survey was designed in English and later translated into Spanish by two researchers who had bilingual backgrounds and who were familiar with the qüestions being asked, as well as the nature of the research. The survey was validated by an ASD expert from IDAPP and pilot tested with three families with children diagnosed with ASD, which were not included in the final sample. Accordingly, minor revisions were made.

Being an explanatory study, an analytical tool with explanatory power such as logistic regression was chosen (Ayçaguer \& Utra, 2004). Pallant (2013, p. 178) suggests that "logistic regression allows you to assess how well your set of predictors variables explains your categorical dependent variable." In this study, the dependent variable was "intention to travel to accessible accommodation." For this study, intention to travel is formed by overcoming intrinsic, interactive, and environmental constraints, as the willingness of the family to travel to accessible accommodation. The dependent categorical variable was measured as follows: "willingness to travel to accessible accommodation: yes/no." Open-ended questions were categorised using content analysis to identify participants' critical incidents when travelling and suggestions to accommodation providers.

To analyse the results, missing values analysis was conducted before proceeding with a mulivariate analysis that was performed using a logistic regression model. A logistic regression model was developed using SPSS software in order to understand intention to travel according to the factors of influence: intrinsic, interactional, and environmental constraints. The entry method was applied: explanatory variables were entered into the formula at the same time. The intrinsic dimension was measured towards five items adopted from Lee et al. (2012): fear of not getting along with other people, travel imposes requirements beyond our capabilities, fear of causing others' discomfort or inconvenience, being in a situation where we need others' help to do something, and fear of needing medical assistance. The interactional dimension was measured towards three items adopted from Lee et al. (2012; fear to receive others' burdensome glances, fear to being ignored by others, and fear of being object of others' interest) and one item related to the specificity of the study (fear of social exclusion of the child). The environmental dimension was measured towards eight items: express check-in and check-out, accessible rooms to people on the ASD, silent rooms, express access to restaurant services, adapted menus to allergies and special dietary requirements, trained staff, personalised service adapted to the needs of the collective, and leisure activities adapted to children on ASD, adopted from Figuereido et al. (2012), Lee et al. (2012), and Darcy (2010). For all three dimensions, each item was measured with a 5-point scale. A factorial analysis was conducted in order to group items in a single quantitative variable.

\section{FINDINGS AND DISCUSSION}

Descriptive statistics were used to obtain the demographic variables of the respondents and profiles of the children (Table 1). A higher female percentage (76.27\%) answered the questionnaire. The majority of the sample had family parties of four members $(52.54 \%)$, were married $(80.51 \%)$, attained university level $(45.76 \%)$, and had a monthly household income between 1,000 and 2,999 Euros (72.63\%). As for the children on ASD, $77.96 \%$ were males and $45.76 \%$ aged 6 to 10 years old. The severity of disorder varied; $60.17 \%$ reported between $34 \%$ and $65 \%$. As for travelrelated characteristics of the sample, the majority $(93.22 \%)$ had overnight travel 
experiences over the last 3 years, and $57.63 \%$ had undertaken one to five family trips in the same period; moreover, $44.97 \%$ had an average length of stay from four to seven nights.

For this study, an exploratory (EFA with SPSS) and confirmatori (CFA; EQS) analyses were conducted to check the validity and reliability of the scale. When exploratory factor analysis is conducted in SPSS, measures of sampling adequacy are requested by checking the boxes for Kaiser - Meyer - Olkin (KMO) and Bartlett's test of sphericity.

Table 1.

General Characteristics of the Sample $(n=117)$

\begin{tabular}{lll}
\hline Variables & Categories & $\%$ \\
\hline Gender & Male & $23.72 \%$ \\
Number of family members & Female & $76.27 \%$ \\
& 2 & $4.24 \%$ \\
& 3 & $38.13 \%$ \\
& 4 & $52.54 \%$ \\
Marital status & 5 & $6.78 \%$ \\
& +5 & 0 \\
Education & Single & $7.63 \%$ \\
& Married & $80.51 \%$ \\
& Divorced/Separated & $11.86 \%$ \\
Monthly household income & Widowed & 0 \\
& High School & $16.95 \%$ \\
& Vocational Studies & $27.96 \%$ \\
Gender (child) & University & $45.76 \%$ \\
Age (child & Postgraduate & $9.32 \%$ \\
& 1000-2999 Euros & $5.26 \%$ \\
& More than 3000 Euros & $72.63 \%$ \\
& Male & $22.10 \%$ \\
& Female & $77.96 \%$ \\
& 0-5 years & $22.03 \%$ \\
& 6-10 years & $16.95 \%$ \\
& $11-15$ years & $45.76 \%$ \\
& 16-18 years & $27.97 \%$ \\
& Less than 33\% & $9.32 \%$ \\
& 34\% to 65\% & $12.71 \%$ \\
& More than 65\% & $60.17 \%$ \\
& & $27.12 \%$ \\
\hline \multirow{3}{*}{ Sevity of disability } & & \\
& &
\end{tabular}


KMO's values greater than 0.8 lead to a good factor analysis. Added to this, Bartlett's test should be less than 0.05 (Pallant, 2013). Then the most common extraction technique to identify the number of underlying dimensions was applied, called the principal component analysis. Finally, Cronbach's a measures the reliability of the measurement scale. Usually, indexes are considered to be satisfactory when they are higher than 0.6 (Malhorta, 1993, in Halkos \& Matsiori, 2012) or 0.7 (Nunnally, 1978, in Halkos \& Matsiori, 2012).

The goodness of fit of the model was ascertained using a Hosmer and Lemeshow goodness - of - fit test, producing a Chi-square $\left(\chi^{2}\right)$ value of 12.234 (significance equal to 0.141 ; see Table 2). The nonsignificance of this value at the 0.05 level meant that the fit was appropriate, as the observed and predicted classification lacked significant discrepancy. The Ómnibus test of the model's overall Chi-square value produced a significance of $\chi^{2}=0.015$, meaning overall fitness was significant as well. The results demonstrated the efficacy of the model to differentiate those who intended to travel more if accommodation is accessible and those who do not with an assurance of statistical significance. In addition, the model correctly classified $36.8 \%$ of those who were willing to travel and $90 \%$ of those who are not. The model had a general explanatory power of $71.3 \%$ (see Table 2 ).

Table 2.

Logistic Regression Model

\begin{tabular}{lll} 
Variables & B & Wald \\
\hline Constant & $-2,557$ & $8733^{* * *}$ \\
Intrinsic constraints &, 489 & $4,688^{* *}$ \\
Interactional constraints & -4.11 & $3,467 *$ \\
Enviromental constraints & $-0,72$ &, 104 \\
Disability Degree &, 862 & $5,309 * *$ \\
Ómnibus test & $\chi^{2} 0,015$ & \\
Nagelkerke's R Square &, 149 & \\
Cox and Snell &, 108 & \\
-2Log likelihood & 127,746 & \\
Hosmer and Lemeshow & $\chi^{2} 12,234$ & \\
& $\mathrm{df8}$ & \\
& Sig., 141 & \\
Overall Percentage Correctly Classified & $\mathbf{7 1 , 3}$ & \\
\hline$* p<0.1 ; * * p<0.05 ; * * * p<0.01$ & &
\end{tabular}

Earlier research focused on generic disabilities, whereas this study is aligned with research against a one-size-fits all solution (Burnett \& Baker, 2001; Darcy, 2010; Darcy et al., 2010; Figuereido et al., 2012; Michopoulou et al., 2015). Thus, it included constraints specific to the ASD condition (see Hypotheses 1,2, and 3). Regarding Hypothesis 1, reliability analysis of "intrinsic constraints" factor was displayed. It revealed a Cronbach $\alpha$ of 0.805 . The value showed an acceptable internal consistency. The factor analysis revealed that the KMO criterion for sampling adequacy was equal to 0.803 and Bartlett's test of sphericity was equal to 187.703 (with a $p$ value of .000 and 10 degrees of freedom). This shows that the procedure was appropriate in this case. The factor intrinsic constraints explained the $56.83 \%$ of the total variation in the data. The results proved to be significant in the case of Hypothesis 1: The travel constraints of intrinsic nature influence the intention to travel to accessible accommodation of families with children on ASD. The positive coefficient for intrinsic constraints indicated that customers with more intrinsic constraints are more likely to travel if accommodation is accessible ( $\beta$ : .489), consistent with priory found direct 
relationship between travel constraints and intention to travel (Burnett \& Baker, 2001; Daniels et al., 2005; Israeli, 2002; Shaw \& Coles, 2004; Turco et al., 1998; Yau et al., 2004). As for the open-ended questions, a high number of mentions of critical incidents were related to other guests complaining about the child's behaviour, as "fear of causing others discomfort or inconvenience." This goes in line with reported lack of support in dealing with the behaviour of the child diagnosed with ASD and a great public lack of understanding and empathy for children with autism, especially regarding the nature of their condition (Amet, 2013). As for suggestions to accommodation providers, there was an overwhelming high response to request training of the accommodation's staff, as increasing "sensitivity." In this line, autism-friendly staff proposals were one of the key findings at Amet's (2013) study also consistent with Baker et al. (2012) and Poria et al. (2011) demonstrating that the staff attitude affects the experience.

Concerning Hypothesis 2, reliability analysis of the scale to measure "interactive constraints" revealed that Cronbach was 0.902. The value showed an acceptable internal consistency. The factor analysis revealed the KMO criterion for sampling adequacy was equal to 0.831 and Bartlett's test of sphericity was equal to 301.753 (with a $p$ value of .000 and six degrees of freedom). This showed the procedure was appropriate in this case. The factor interactive constraints explained the $77.35 \%$ of the total variation in the data. Results indicated that the travel constraints of interactive nature influence the intention to travel to accessible accommodation of families with children on ASD; it was not confirmed. Families with more interactive constraints were less likely to travel to accessible accommodation. The dimensions analysed were burdensome glances, fear to being ignored by others, fear of being object of others' interest, and fear of social exclusion of the child. These constraints are related to the interaction of staff and other guests towards the family and the child. As Lee et al. (2012) pointed out, it may not always be the case that there is a direct relation between travel constraints and intention to travel. Several authors addressed overt or subtle discrimination, social exclusion, and ignorance (Shaw \& Coles, 2004; Yau et al., 2004) as a source of stress to travellers with disabilities. However, in this specific case, families rejected the hypothesis, arguably because the interaction of staff or other guests will not be different or beneficial at accessible accommodation. In-depth interviews would be necessary to further explore these findings, which are different from those initially expected.

As for Hypothesis 3, reliability analysis of the scale to measure "environmental constraints" revealed that Cronbach was 0.952. The value showed an acceptable internal consistency. The factor analysis revealed the KMO criterion for sampling adequacy was equal to 0.931 and Bartlett's test of sphericity was equal to 845.393 (with a $p$ value of .000 and 28 degrees of freedom). This showed the procedure was appropriate in this case. The factor environmental constraints explained the $75.21 \%$ of the total variation in the data. In view of the results, that the travel constraints of environmental nature influence the intention to travel to accessible accommodation of families with children on ASD was not significant. Although the results were not significant as for the logistic regression model applied, the open-ended answers referred extensively to dimensions included in this constraint. The critical incidents mostly stated were related to dietary needs (limited offer, not adapted menus) in line with the dimension "adapted menus to allergies and special dietary requirements," followed by problems at waiting times at check-in (dimension "express check-in and check-out") and at the restaurants (dimension "express access to restaurant services"). A high number of mentions had to do with the nonadapted leisure offer (dimension "leisure activities adapted to children on the ASD"). Few comments referred to the restaurant personnel service (dimension "express access to restaurant services") or to 
the level of noise in the room (dimension "silent rooms"). Some families mentioned incidents with rooms that could not be locked. When asked about coping strategies, the families found no solution was provided by the accommodation company to their special requests; thus, some families formally complained or, in a specific case, decided to leave the hotel. In few cases, they were offered apologies. As for issues related to "express access to restaurant services," families reported that they visited the restaurant very early or very late to avoid queues. In line with the dimension "personalized service adapted to the need of the collective," families mentioned to have asked to be seated at a silent table. To reheat food was also mentioned as a dietary need. As for suggestions to accommodation providers, a high number of respondents mentioned specific training aimed at staff dedicated to the kid's leisure activities. At a great extent, requests related to adapted rooms were mentioned (i.e., away from elevators and locks) and to facilitating waiting times (express check-in and check-out and restaurant). Reducing queuing time is in line with Amet's (2013) findings. Mentions linked to the restaurant offerings (adapted menus, quiet areas, and visuals) should also be noted. Most of the information provided is related to the dimensions of environmental nature, arguably because those are tangible, visible, dependent on others (the hotel's management), and observable at first glance and do not require such a self-knowledge or personal connection, as in the case of the intrinsic or interactive constraints.

For improving the tourist experience of families travelling with a child diagnosed with ASD, it is better to regard the disorder as one of the features that characterises a certain customers' segment rather than as an impairment. Universal service supply guarantees a greater independence for these families considering that their specific needs, such as special menus, express check-in or access, and silent rooms, have been already taken into account. Michopoulou et al. (2015) rightly point out that for providing inclusive models of accessible tourism, stakeholder collaboration is crucial. Accommodating for individual disabilities requires a higher level of service provision (McKercher \& Darcy, 2018). The adaptations needed are simple so a social inclusive model where the needs are not treated as special but, instead, are considered in the universal design of the space and the service are plausible (Zajadacz, 2015), given that customising the service provision is something the hospitality providers are used to do (McKercher \& Darcy, 2018). In this line, accessible tourism becomes more than suport to a specific community, it may translate into specific new codes of practice to develop hospitality offers in an inclusive way, in line with the views of Michopoulou et al. (2015). From this perspective, accessible tourism is a business opportunity as much as it becomes a chance to promote social inclusion (Figuereido et al., 2012).

Concerning Hypothesis 4, it proved to be significant. The severity of the disorder increases the intention to travel to accessible accommodation ( $\beta$ : .862). Consequently, the higher the disorder degree of the child, the higher the probability of customers to travel if accommodation were accessible. Despite the fact that at first, a high degree of disorder might be associated with less intention of travel due to the lack of facilities and services, the findings in this study showed that families are longing for accessible accommodation. There is here a clear market opportunity for accommodation providers in terms of making their offer more accessible. As mentioned before, the adaptations are simple and is mostly linked to adapting the service, to training the staff and implementing specific codes of practice. These findings follow the results from Darcy (2010) on the suport needs of people with a higher degree of disability, and it is consistent with $\mathrm{Bi}$ et al.'s (2012) findings that participants with low functioning encountered more accessibility and attitudinal barriers in the accommodation business (applied to physical disability). Findings are aligned with Burnett and Baker (2001) 
where environament-related, accessibility, and activities decision criteria were valued more as disability severity increased.

As McKercher and Darcy (2018) and Lee et al. (2012) pointed out, there is not a linear relationship; participation by people with disabilities in tourism activities is a complex issue, and the constraints are at different levels and operate in an interconnected manner. This might explain the findings. Applying the four-tiered framework proposed by Mc Kercher \& Darcy (2018), it is clear that, as for Tier 2, issues faced by all people with people with disabilities were very present, specifically ignorance and attitude. Furthermore, as for Tier 3, issues unique to specific disabilities (intellectually or physically disabled children) were in line with their findings such as suitable leisure kid's activities, behavioural problems, and standing in line difficulties. As for Tier 4, moderating factors of impairment effects, in this case, the severity of the child's disorder, showed that it increases the family's intention to travel to accessible accommodation.

\section{CONCLUSIONS}

Results indicated that the intrinsic constraints and the severity of the condition influence the intention to travel to accessible accommodation and confirmed that families with a child diagnosed with ASD are a heterogeneous market, with families who are more willing to travel if accommodations are accessible and families who are not. As mentioned throughout the study, the ASD is a disorder that has its own specific characteristics such as communicative and social difficulties, and learning and information-processing limitations. Families with children diagnosed with ASD do not just aspire to stay in a hotel but fully live their tourism experience with minimum constraints. For this to be possible, researchers and accommodation providers need to fully understand the ASD, go in-depth in the experiences of the families while travelling, and are required to propose appropriate strategies and tools to help improve the tourism experiences of this group.

This study contributes to the literature on accessible tourism by responding to the need to gain greater understanding about the uniqueness of this specific market segment (families travelling with children diagnosed with ASD), consistent with research against one-size-fits-all solution (Burnett \& Baker, 2001; Darcy, 2010; Darcy et al., 2010; Figuereido et al., 2012; Michopoulou et al., 2015). Specifically, this research extends earlier knowledge on travel constraints that did not include developmental disorders (Lee et al., 2012; Figuereido et al., 2012; Darcy, 2010), and it also advances knowledge on the constraints' influence to intentions to travel to accessible accommodation.

The research findings have several practical implications. The results may help accommodation providers in their attempt to provide improvements in access to services, safety, and customer satisfaction. For the accommodation providers, better training on the ASD condition and their unique needs (McKercher \& Darcy, 2018), as well as greater exposure to members of the community, is highly recommended. In particular, the ASD is still unknown by a significant part of the Spanish society, and it continues to be stigmatised. Being as it is a "hidden disorder," in the sense that it is not easily identified at a first sight, the challenges are greater. Besides that, behavioural issues associated with the ASD may also impact attitudes of professionals in the field. These attitudes will be harder to change, if the condition is not understood properly. There is immense potential for partnerships between health professionals, 
associations, and companies to address leisure opportunities for families with a child diagnosed with ASD (Sedgley et al., 2017). Similarly, the study could also be of interest to other industry stakeholders that are participant to the tourism experience of families with a child diagnosed with ASD, as for providing inclusive models of accessible tourism stakeholder collaboration is crucial (Michopoulou et al., 2015). The uptake of recent legislative requirements on making tourism accessible for all transcend the earlier physical and sensory disabilities to include developmental disorders (Connell \& Page, 2019) offers a positive outlook.

Regarding the limitations of this study, this exploratory study has depended on convenience sampling, and thus, the sample might not be representative of the whole population of families travelling with a child diagnosed with ASD. Therefore, it is necessary to be cautious when it comes to the results generalisation. Furthermore, this study treated families as a homogenous group. Mainly, participating famílies had children with a moderate or severe condition; thus, highfunctioning children and their families are not represented, and their situation might be very different than the one portrayed in the study. Particular cases with their specificities were not examined highlighting the crucial need for further in-depth research of this issue. "Since tourism experiences are journeys of mixed emotions" for families with children diagnosed with ASD (Sedgley et al., 2017, p. 22), it would be advisable to explore in more details the dimensions of this study by means of mobile ethnography and in-depth interviews. In addition, all families participating were from Catalonia (Spain); thus, further crosscultural research would be advisable (Poria et al., 2011). Finally, intention to travel was measured through a single item: willingness to travel to accessible accommodation (yes/no). It can be argued the need to measure intention to travel applying a more nuanced construct, which can be an issue to consider for future fieldworks. Further research may also expand upon the development of enabling practices (Michopoulou et al., 2015; Sedgley et al., 2017) to monitor the families' travelling patterns and understand their emotional engagement. It is also recommendable to explore replicating this study to other forms of mental, cognitive, or developmental disorders as well as addressing other subsectors of the tourism industry (i.e., airlines, airports, recreation parks, and museums).

\section{REFERENCES}

Allan, M. (2015). Accessible tourism in Jordan: Travel constrains and motivations. European Journal of Tourism Research, 10(January), 109-119.

American Psychiatric Association (2013). Diagnostic and statistical manual of mental disorders (DMS - 5). Chicago: American Psychiatric Pub.

Amet, L. (2013). Holiday, what holiday? Vacation experiences of children with autism and their families. Autism, 3(3), 123.

Autism Speaks (2010). First 100 days kit. USA: Autism speaks Inc.

Ayçaguer, L., \& Utra, I. (2004). Regresión logística. Madrid: La Muralla SA.

Bi, Y., Card, J. A., \& Cole, S. T. (2007). Accessibility and attitudinal barriers encountered by chinese travellers with physical disabilities. International Journal of Tourism Research, 9, 205-216. https://doi.org/10.1002/itr.603 
Buhalis, D., \& Michopoulou, E. (2011). Information - enabled tourism destination marketing: Addressing the accessibility market. Current Issues in Tourism, 14(2), 145168. https://doi.org/10.1080/13683501003653361

Burnett, J. J., \& Baker, H. (2001). Assessing the travel - related behaviors of the mobility - disabled consumer. Journal of Travel Research, 40(1), 4-11. https://doi.org/10.1177/004728750104000102

CDC, Centers for Disease Control and prevention. (2018). CDC|Facts| Autism spectrum disorder (ASD)|NCBDDD. Retrieved Februrary 12, 2019, from https://www.cdc.gov/ncbddd/autism/data.html

Connell, J., \& Page, S. J. (2019). Case study: Destination readiness for dementia friendly visitor experiences: A scoping study. Tourism Management, 70, 29-41. https://doi.org/10.1016/j.tourman.2018.05.013

Crawford, D. W., \& Godbey, G. (1987). Reconceptualizing barriers to family leisure. Leisure Sciences, 9(2), 119-127. https://doi.org/10.1080/01490408709512151

Crawford, D. W., Jackson, E. L., \& Godbey, G. (1991). A hierarchical model of leisure constraints. Leisure Sciences, 13(4), 309-320.

https://doi.org/10.1080/01490409109513147

Daniels, M. J., Rodgers, E. B. D., \& Wiggins, B. P. (2005). "Travel tales": An interpretive analysis of constraints and negotiations to pleasure travel as experienced by persons with physical disabilities. Tourism Management, 26(6), 919-930. https://doi.org/10.1016/j.tourman.2004.06.010

Darcy, S. (2010). Inherent complexity: Disability, accessible tourism and accommodation information preferences. Tourism Management, 31(6), 816-826. https://doi.org/10.1016/j.tourman.2009.08.010

Darcy, S., Cameron, B., \& Pegg, S. (2010). Accessible tourism and sustainability: A discussion and case study. Journal of Sustainable Tourism, 18(4), 515-537. https://doi.org/10.1080/09669581003690668

Darcy, S., \& Dickson, T. J. (2009). A whole - of - life approach to tourism: The case for accessible tourism experiences. Journal of Hospitality and Tourism Management, 16(1), 32-44. https://doi.org/10.1375/jhtm.16.1.32

Darcy, S., \& Pegg, S. (2011). Towards strategic intent: Perceptions of disability service provision amongst hotel accommodation managers. International Journal of Hospitality Management, 30(2), 468-476. https://doi.org/10.1016/j.ijhm.2010.09.009

Dawson, G. (1996). Brief report: Neuropsychology of autism: A report on the state of the science. Journal of Autism and Developmental Disorders, 26(2), 179-184. https://doi.org/10.1007/BF02172008

Decrop, A. (2006). Vacation decision - making. Wallingford, UK: CABI Publishing.

Dwyer, L., \& Darcy, S. (2008). Economic contribution of disability to tourism in Australia. In S. Darcy, B. Cameron, L. Dwyer, T. Taylor, E. Wong, \& A. Thomson 
(Eds.), Technical Report 90040: Visitor accessibility in urban centres (pp. 15-21). Gold Coast: Sustainable Tourism Cooperative Research Centre.

Early Intervention Consulting LLC[EIC] (2011). An introduction to autism and early intervention. V1.0, USA.

Elsabbagh, M., Divan, G., Koh, Y. - J., Kim, Y. S., Kauchali, S., Marcín, C., \& Fombonne, E. (2012). Global prevalence of autism and other pervasive developmental disorders. Autism Research: Official Journal of the International Society for Autism Research, 5(3), 160-179. https://doi.org/10.1002/aur.239

Emira, M., \& Thompson, D. (2011). In the quest for their trust: The perceptions of families on accessing leisure services for disabled children. Leisure Studies, 30(1), 3348. https://doi.org/10.1080/02614367.2010.506648

European Commission. (2013). Economic Impact and Travel Patterns of accessible tourism in Europe.

European Commission. (2016). Mapping and performance check of the supply side of tourism education and training. Retrieved from http://euskillspanorama.cedefop.europa.eu/en/useful resources/mappingandperformance-check-supply-side-tourism-education-and-training

Figueiredo, E., Eusébio, C., \& Kastenholz, E. (2012). How diverse are tourists with disabilities? A pilot study on accessible leisure tourism experiences in Portugal. International Journal of Tourism Research, 14, 531-550. https://doi.org/10.1002/itr.1913

Halkos, G., \& Matsiori, S. (2012). Determinants of willingness to pay for coastal zone quality improvement. The Journal of Socio - Economics, 41(4), 391-399. https://doi.org/10.1016/..socec.2012.04.010

Hamed, H. M. (2013). Tourism and autism: An initiative study for how travel companies can plan tourism trips for autistic people. American Journal of Tourism Management, 2(1), 1-14. http://doi.org/10.5923/j.tourism.20130201.01

Hausemer, P., Ambrose, I., Ito, K. \& Auzinger, M. (2012). Mapping skills and training needs to improve accessibility in tourism services.

Israeli, A. (2002). A preliminary investigation of the importance of site accessibility factor for disabled tourists. Journal of Travel Research, 41(1), 101-104. https://doi.org/10.1177/004728750204100114

Jang, S., Bai, B., Hu, C., \& Wu, C. (2009). Affect, travel motivation, and travel intention: A senior market. Journal of Hospitality and Tourism Research, 33(1), 51-73. https://doi.org/10.1177/1096348008329666

Kah, J., Lee, C. - K., \& Lee, S. - H. (2016). Spatial - temporal distances in travel intention - behavior. Annals of Tourism Research, 57, 160-175.

https://doi.org/10.1016/j.annals.2015.12.017 
Kim, S., \& Lehto, X. Y. (2013). Leisure travel of families of children with disabilities: Motivation and activities. Tourism Management, 37, 13-24. http://doi.org/10.1016/i.tourman.2012.12.011

Kopetz, P., \& Endowed, E. (2012). Autism worldwide: Prevalence, perceptions, acceptance, action. Journal of Social Sciences, 8(2), 196-201.

Lee, B. K., Agarwal, S., \& Kim, H. J. (2012). Influences of travel constraints on the people with disabilities' intention to travel: An application of Seligman's helplessness theory. Tourism Management, 33(3), 569-579. https://doi.org/10.1016/j.tourman.2011.06.011

Lugosi, P., Robinson, R. N. S., Golubovskaya, M., Foley, L., \& Harwell, J. (2016). Experiencing parenthood, care and spaces of hospitality. The Sociological Review, 64, 274-293. https://doi.org/10.1111/1467-954X.12330

March, R. G., \& Woodside, A. G. (2005). Tourism behavior: Travelers' decisions and actions. Cambridge: CABI Publishing.

McKercher, B., \& Darcy, S. (2018). Re-conceptualizing barriers to travel by people with disabilities. Tourism Management Perspectives, 26, 59-66.

https://doi.org/10.1016/j.tmp.2018.01.003

McKercher, B., Packer, T., Yau, M. K., \& Lam, P. (2003). Travel agents as facilitators or inhibitors of travel: Perceptions of people with disabilities. Tourism Management, 24(4), 465-474. https://doi.org/10.1016/S0261-5177(02)00107-3

Michopoulou, E., Darcy, S., Ambrose, I., \& Buhalis, D. (2015). Accessible tourism futures: The world we dream to live in and the opportunities we hope to have. Journal of Tourism Futures, 1(3), 179-188. https://doi.org/10.1108/JTF-08-2015-0043

National Institute on Deafness and Other Communication Disorders NIDCD (2010). NIDCD Fact Sheet: Communication problems in children with autism. NIH Publication No. 10 - 4315, USA.

O'Neill, M., \& Ali Knight, J. (2000). Disability tourism dollars in Western Australia hotels. FIU Hospitality Review, 18(2), 72-88.

Pallant, J. (2013). SPSS Survival Manual: A Step by Step Guide to Data Analysis Using SPSS. New York, USA: Open University Press.

Perry, H. \& Kozub, M. (2011). Family travel experiences when one membre has a developmental disability. Proceedings of the 2011 Northeastern Recreation Research Symposium. htttp://scholarworks.umass.edu/nerr/ 2011/Papers/17/.

Poria, Y., Reichel, A., \& Brandt, Y. (2011). Dimensions of hotel experience of people with disabilities: An exploratory study. International Journal of Contemporary Hospitality Management, 23(5), 571-591. https://doi.org/10.1108/09596111111143340

Schänzel, H., Yeoman, I., \& Backer, E. (Eds,). (2012). Family tourism: multidisciplinary perspectives. Clevedon: Channel View. 
Sedgley, D., Pritchard, A., Morgan, N., \& Hanna, P. (2017). Tourism and autism: Journeys of mixed emotions. Annals of Tourism Research, 66,14-25.

https://doi.org/10.1016/j.annals.2017.05.009

Shaw, G., \& Coles, T. (2004). Disability, holiday making and the tourism industry in the UK: A preliminary survey. Tourism Management, 25(3), 397-403. https://doi.org/10.1016/S0261-5177(03)00139-0

Smith, R. W. (1987). Leisure of disabled tourists-Barriers to participation. Annals of Tourism Research, 14(3), 376-389. https://doi.org/10.1016/0160-7383(87)90109-5

Stuhl, A., \& Porter, H. (2015). Riding the waves: Therapeutic surfing to improve social skills for children with autism. Therapeutic Recreation Journal, XLIX(3), 253-256.

Tantawy, A., Kim, W. G., \& Pyo, S. (2005). Evaluation of hotels to accommodate disabled visitors. Journal of Quality Assurance in Hospitality and Tourism, 5(1), 91-101. https://doi.org/10.1300/J162v05n01 07

Turco, D., Stumbo, N., \& Garncarz, J. (1998). Tourism constraints for people with disabilities. Parks and Recreation, 33(9), 78-84.

World Health Organization. (2014). World Report. World report on disability. Retrieved from www.who.int

World Tourism Organization \& ACS, F. (2015). Manual on Accessible Tourism for All.

Yau, M., McKercher, B., \& Packer, T. (2004). Travelling with a disability: More than an access issue. Annals of Tourism Research, 31(4), 946-960.

https://doi.org/10.1016/j.annals.2004.03.007

Zajadacz, A. (2015). Evolution of models of disability as a basis for further policy changes in accessible tourism. Journal of Tourism Futures, 1(3), 189-202.

https://doi.org/10.1108/JTF-04-2015-0015 